\title{
Performance and Combustion Characteristics of Single Cylinder Diesel Engine Running on Karanja Oil/Diesel Fuel Blends
}

\author{
Siddalingappa R. Hotti, Omprakash Hebbal \\ PDA College of Engineering, Gulbarga, India \\ E-mail: hottisr@gmail.com \\ Received January 25, 2011; revised March 8, 2011; accepted March 17, 2011
}

\begin{abstract}
The present paper investigates the performance and combustion characteristic of single cylinder, naturally aspirated, water cooled, DI diesel engine running on karanja oil (K100) and blends with diesel K10, K15, and K20 and the experimental results were compared with that of diesel. The results showed that the fuel properties of K100, density, viscosity, flash point and carbon residue were found to be higher than that of diesel and calorific value is lower than that of diesel. Based on performance and combustion characteristics of the various blends, the optimum blend was found to be K15.
\end{abstract}

Keywords: Vegetable Oil, Karajan Oil, Combustion Characteristics, Injector Opening Pressure, Injection Timing

\section{Introduction}

India with the high rate of economic growth and increase in the population is the significant consumer of energy resources. India lacks in sufficient energy reserves and dependent on oil imports, but India has an abundant resource of vegetable oils. The use of vegetable oil in a diesel engine is not a new concept. In fact early engines were demonstrated with straight vegetable oils (SVO). Vegetable oils were proved to be very costlier during those days. However due to limited reserves of fossil fuels, escalation nature of diesel fuel prices and increase in environmental pollution, created a renewed interest of research in vegetable oil as substitute fuel for diesel engines. Vegetable oil is easily available, renewable and environment friendly. However major disadvantage of vegetable oil is its viscosity, which is much higher than that of diesel.

Bajpai et al. [1] tested performance and emission characteristics of karanja SVO blending with diesel and concluded that without major engine modifications blending up to 10 percentages can be utilized in the existing engine. In order to study the effect of injector opening pressure (IOP) on performance, emission and combustion characteristics of diesel engine running on blends of karanja SVO Venkanna et al. [2] estimated the ignition delay period (IDP) and heat release rate at $75 \%$ load and found that IDP increases with increase in blend percentage from $20 \%$ to $30 \%$ and noticed decrease in net heat release rate. Avinash Agarwal et al. [3] carried out experiments on diesel engine running on karanja oil and their blends. Even without preheating engine was running successfully, they concluded that performance and emission characteristics are well comparable with that of diesel and also up to $50 \%$ with and without preheating can be used in diesel engines. Other researchers, [4-6] conducted the performance and emission characteristics of karnaja biodiesel.

Karnja is a forest based tree-borne non-edible oil with a, production potential of 135000 million tones [4]. Karanja tree grows all over the country. In parts of India, this tree is also known as pongamia, belongs to the family of Leguminaceae. It is a medium sized tree that attains a height of about $18 \mathrm{~m}$ and a trunk diameter greater than $50 \mathrm{~cm}$. The fresh extracted oil is yellowish orange to brown and rapidly darkens on storage [6].

The objective of this paper is to investigate, performance and combustion characteristics of single cylinder, naturally aspirated, DI diesel engine running on Karanja oil (K100) and its blends K10 (10\% Karanja oil blended with 90\% diesel on volume basis), K15 (15\% Karanja oil blended with 85\% diesel on volume basis) and K20 (20\% 
Karanja oil blended with $80 \%$ diesel on volume basis).

\section{Experimental Setup and Test Procedure}

To study the performance and combustion characteristics, a typical computerized four-stroke, single cylinder, water cooled naturally aspirated direct injection diesel engine was selected. The detailed technical specifications of engine are as given in Table 1.

Figure 1 Shows the schematic diagram of engine set up. The setup enables study of engine performance for brake power, indicated power, frictional power, BMEP, IMEP, brake thermal efficiency, indicated thermal efficiency, mechanical efficiency, volumetric efficiency, specific fuel consumption, air fuel ratio, and heat balance. Lab-view based engine performance analysis software package "Engine soft" is provided for on line performance evaluation.

\section{Estimation of Heat Release Rate}

The heat release rate is estimated by computing the ensemble average of in-cylinder pressure, recorded at every crank angle for number of cycles. For direct-Injection

Table 1. Technical specifications of the engine.

\begin{tabular}{|c|c|}
\hline Manufacturer & Kirloskar Oil Engines Ltd., India \\
\hline Model & TV_SR II, naturally aspirated \\
\hline Engine & $\begin{array}{l}\text { Single cylinder, direct injection } \\
\text { diesel engine }\end{array}$ \\
\hline $\begin{array}{c}\text { Bore/stroke/compression } \\
\text { ratio }\end{array}$ & $87.5 \mathrm{~mm} / 110 \mathrm{~mm} / 17.5: 1$ \\
\hline Rated power & $5.2 \mathrm{~kW}$ \\
\hline Speed & $1500 \mathrm{rpm}$, constant \\
\hline $\begin{array}{c}\text { Injection } \\
\text { pressure/advance }\end{array}$ & 200bar/23 degree before TDC \\
\hline Dynamometer & Eddy current \\
\hline Type of starting & Manually \\
\hline Air flow measurement & Air box with 'U' tube \\
\hline Exhaust gas temperature & RTD thermocouple \\
\hline Fuel flow measurement & Burette with digital stopwatch \\
\hline Governor & $\begin{array}{l}\text { Mechanical governing } \\
\text { (Centrifugal type) }\end{array}$ \\
\hline Sensor response & Piezo electric \\
\hline Time sampling & 4 micro seconds \\
\hline Resolution crank & 1 degree crank angle \\
\hline Angle sensor & $\begin{array}{l}360 \text { degree encoder with } \\
\text { resolution of } 1 \text { degree }\end{array}$ \\
\hline
\end{tabular}

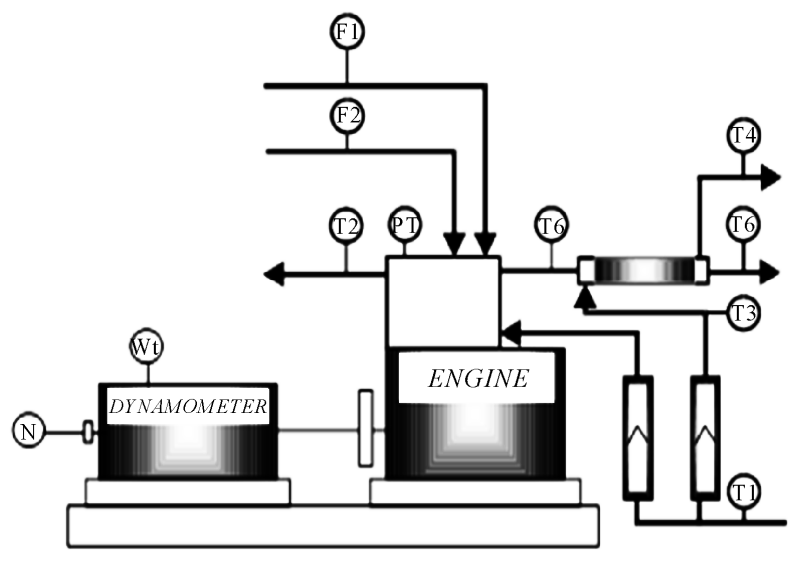

Figure 1. Engine test setup. PT-Pressure Transducer, NRotary encoder, Wt-Weight, F1-Fuel flow, F2-Air flow, F3Jacket water flow, F4-Calorimeter water flow, T1-Jacket water inlet temperature, T2-Jacket water outlet temperature, T3-Calorimeter water inlet temperature, T4-Calorimeter water outlet temperature, T5-Exhaust gas to calorimeter temperature, T6-Exhaust gas from calorimeter temperature.

engine, the cylinder contents are a single open system and heat release rate is calculated by applying the first law of thermodynamics using the following equation [7].

$$
\frac{\mathrm{d} Q_{n}}{\mathrm{~d} t}=\frac{\mathrm{d} Q_{c n}}{\mathrm{~d} t}-\frac{\mathrm{d} Q_{n t}}{\mathrm{~d} t}
$$

where, $\frac{\mathrm{d} Q_{n}}{\mathrm{~d} t}$ is the apparent net heat release rate, $\frac{\mathrm{d} Q_{c n}}{\mathrm{~d} t}$ is the gross heat release rate and $\frac{\mathrm{d} Q_{n t}}{\mathrm{~d} t}$ is the heat-transfer rate to the walls.

If further the contents of the cylinder are modeled as an ideal gas the Equation (1) becomes

$$
\frac{\mathrm{d} Q_{n}}{\mathrm{~d} t}=p \frac{\mathrm{d} v}{\mathrm{~d} t}+m c_{v} \frac{\mathrm{d} T}{\mathrm{~d} t}
$$

For the ideal gas law, $p V=m R T$ with $R$ assumed constant, it follows that

$$
\frac{\mathrm{d} p}{p}+\frac{\mathrm{d} V}{V}=\frac{\mathrm{d} T}{T}
$$

Equation (3) can be used to eliminate $T$ from Equation (2) to give

$$
\frac{\mathrm{d} Q_{n}}{\mathrm{~d} t}=\left(1+\frac{c_{v}}{R}\right) p \frac{\mathrm{d} V}{\mathrm{~d} t}+\frac{C_{v}}{R} V \frac{\mathrm{d} p}{\mathrm{~d} t}
$$

Then, apparent net heat release rate is given by the Equation (5), where, $\gamma=c_{p} / c_{v}$ is the ratio of specific heats.

$$
\frac{\mathrm{d} Q_{n}}{\mathrm{~d} t}=\frac{\gamma}{\gamma-1} p \frac{\mathrm{d} V}{\mathrm{~d} t}+\frac{1}{\gamma-1} V \frac{\mathrm{d} p}{\mathrm{~d} t}
$$




\section{Results and Discussion}

The experiments were carried out on a test engine running on diesel, K10, K15, K20 and K100 fuels in order to investigate the performance and combustion characteristics. All the experiments were conducted at rated engine speed of $1500 \mathrm{rpm}$ under varying load conditions of $0,20 \%, 40 \%, 60 \%, 80 \%, 100 \%$ of rated load for $\mathrm{K} 10$, K15, K20 fuels and 0, 25\%, 50\%, 75\%, 100\% of rated load for K100 and diesel fuels. After completion of each experiment the engine was run on diesel in order to flush the fuel in the fuel line. The performance parameters considered are brake specific fuel consumption, brake thermal efficiency and exhaust temperature.

\subsection{Properties of Karanja Oil}

The properties of Karanja oil (K100) was determined in our college laboratory and tabulated in Table 2 . The kinematic viscosity of the Karanja oil was found to be $54.14 \mathrm{~mm}^{2} / \mathrm{s}$, which is more than that of diesel. The density of K100 was more; this may be due to the presence of higher molecular weight triglyceride molecules. The calorific value of the oil was found to be $36470 \mathrm{~kJ} / \mathrm{kg}$, which is lower than that of diesel. This may be due to the difference in the chemical composition or presence of oxygen molecule in the molecular structure of oil. The flash point of $\mathrm{K} 100$ oil was $>200^{\circ} \mathrm{C}$ which is much higher than that of diesel, which helps in safe storage and transportation. The value of carbon residue was found to be high, which may lead to greater carbon deposits in the combustion chamber.

\subsection{Performance Characteristics}

The variation of brake specific fuel consumption with brake power is as shown in the Figure 2, as the power developed increases the specific fuel consumption de-

Table 2. Properties of Karanja oil in comparison with diesel.

\begin{tabular}{|c|c|c|c|}
\hline Properties & Karanja oil & Diesel [1] & Equipment \\
\hline $\begin{array}{c}\text { Viscosity@ @40ㄷ } \\
\left(\mathrm{mm}^{2} / \mathrm{s}\right)\end{array}$ & 54.14 & 2.87 & $\begin{array}{l}\text { Redwood } \\
\text { Viscometer }\end{array}$ \\
\hline Density gm/cc & 0.930 & 0.850 & $\begin{array}{l}\text { Specific gravity } \\
\text { bottle }\end{array}$ \\
\hline $\begin{array}{c}\text { Calorific value, } \\
\mathrm{kJ} / \mathrm{kg}\end{array}$ & 36,470 & 44,019 & Bomb calorimeter \\
\hline Flash point, ${ }^{\circ} \mathrm{C}$ & $>200$ & 76 & Pensky-Martens \\
\hline $\begin{array}{l}\text { Carbon residue } \\
\text { percentage w/w }\end{array}$ & 1.6 & - & Conradson \\
\hline Type of oil & Non-edible & - & - \\
\hline
\end{tabular}

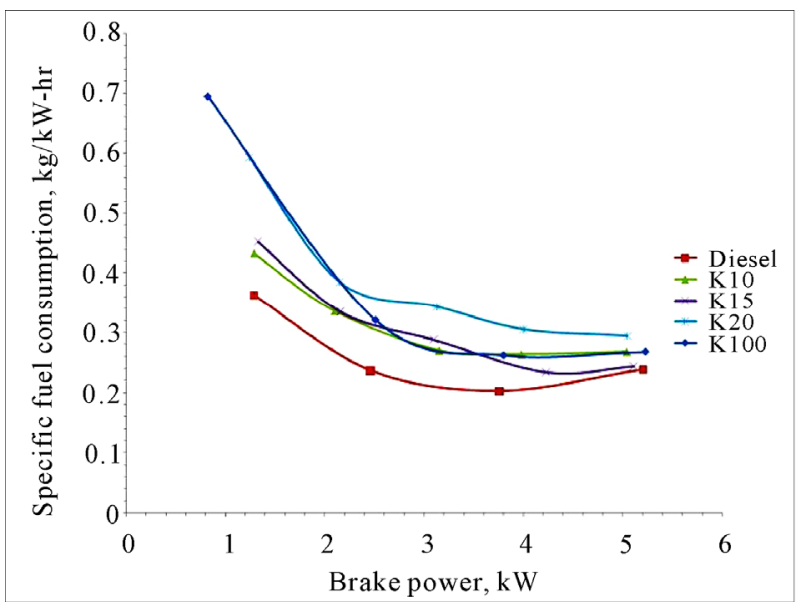

Figure 2. Variation of brake specific fuel consumption with brake power.

creases for all the tested fuels. The specific fuel consumption of blends is more than that of diesel, this is due to lower calorific value of the fuel, and engine consumes more amount of the fuel in order to produce the same out-put power. The specific fuel consumption of K15 is satisfactory as compared to that of diesel at full load.

Figure 3 represents the variation of brake thermal efficiency with brake power developed, thermal efficiency of all the blends are lower than that of diesel, this is attributed to more amount of fuel consumption for blends as compared to diesel. Thermal efficiency is lowest for K20 and thermal efficiency of K15 blend reaches to thermal efficiency of diesel at full load.

The variation of exhaust gas temperature with brake power is as shown in Figure 4. The exhaust gas temperature of all the blends is highest at part load conditions as compared to diesel. This may be due to the shorter premixed combustion period, which increases the after burning period and the gases exit with high temperature, as the load increases the exhaust gas temperature was well comparable with diesel.

\subsection{Combustion Characteristics}

The estimated heat release rate with crank angle is represented in Figure 5, in all the tested fuel the short premixed heat release period is noticed. The heat release rate for all the tested fuel was less than that of diesel this may be attributed to low vaporization, high viscosity and low peak pressure of blends as compared to that of diesel.

Figure 6 Shows the variation of ignition delay with brake power, the ignition delay in diesel engine was defined as crank angle interval between the start of injection and the start of combustion. It is computed based on static start of injection (23 $3^{\circ}$ bTDC) and start of combus- 


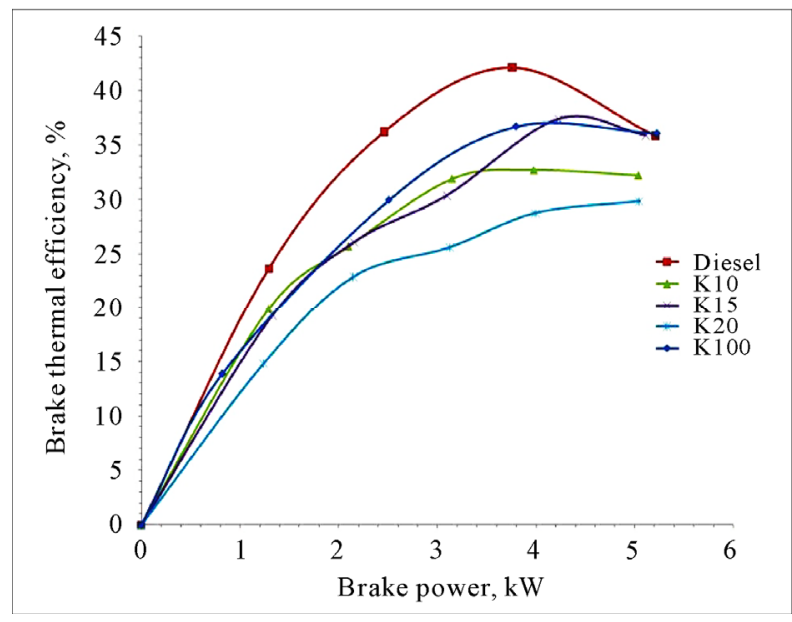

Figure 3. Variation of brake thermal efficiency with brake power.

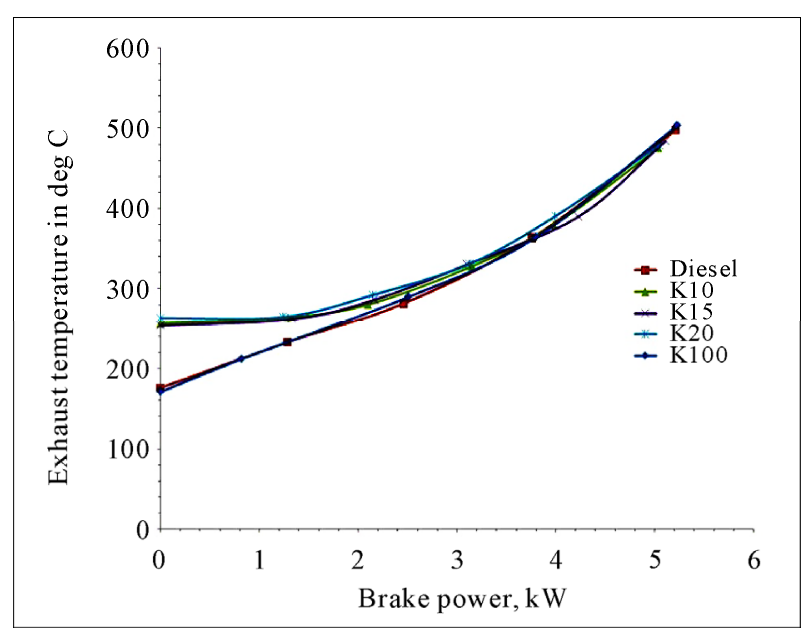

Figure 4. Variation of exhaust gas temperature with brake power.

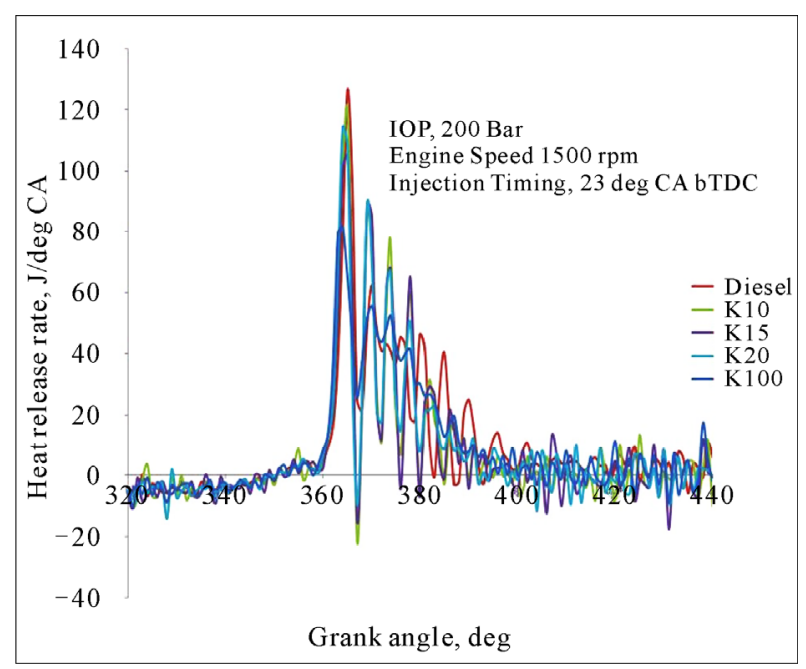

Figure 5. Variation of heat release rate with crank angle at full load.

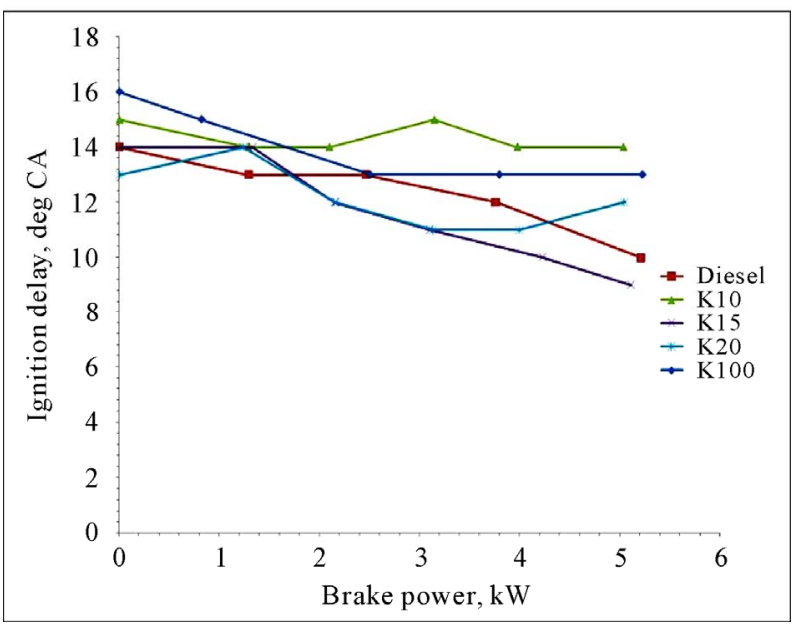

Figure 6. Variation of ignition delay with brake power.

tion. Start of combustion is the point where change of slope in heat release rate is noticed. The ignition delay period was reduced with increase in load for all tested fuels except K20. The ignition delay period was found to be shorter than that of diesel for K15, varying between $14^{\circ} \mathrm{CA}$ to $9^{\circ} \mathrm{CA}$ as against $14^{\circ} \mathrm{CA}$ to $10^{\circ} \mathrm{CA}$ for diesel.

\section{Conclusions}

The conclusions drawn were as follows, based on the fuel properties of K100, the higher amount of carbon residue may lead to carbon deposits on the combustion chamber and viscosity was found to be higher, the high flash point enables the safe storage and transportation. Based on the investigations, the specific fuel consumption to develop the same amount of engine output power was found to be more this may be due to low calorific value of all the blends. The thermal efficiency of K15 was well comparable with that of diesel. Engine ran successfully even on K100 fuel without any engine modifications. Finally based on performance and combustion characteristics it can be seen that K15 was found to be optimum blend. Further investigations are to be carried out at varying IOP and injection timing.

\section{References}

[1] S. Bajpai, P. K. Sahoo and L. M. Das, "Feasibility of Blending Karanja Vegetable Oil in Petro-Diesel and Utilization in a Direct Injection Diesel Engine,” Fuel, Vol. 88, No. 4, 2009, pp. 705-711. doi:10.1016/j.fuel.2008.09.011

[2] B. K. Venkanna, S. B. Wadawadgi and C. V. Reddy, "Effect of Injection Pressure on Performance, Emission and Combustion Characteristics of Direct Injection Diesel Engine Running on Blends of Pongamia Pinnata Linn oil (Honge Oil) and Diesel Fuel,” Agricultural Engineering 
International: The CGIR Ejournal, Vol. 11, May 2009.

[3] A. K. Agarwal and K. Rajamanoharanm, "Experimental Investigations of Performance and Emissions of Karanja Oil and Its Blends in a Single Cylinder Agricultural Diesel Engine,” Applied Energy, Vol. 86, No. 1, 2009, pp. 106-112. doi:10.1016/j.apenergy.2008.04.008

[4] H. Raheman and A. G. Phadatare, "Diesel Engine Emissions and Performance from Blends of Karanja Methyl ester and Diesel,” Biomass and Bioenergy, Vol. 27, No. 4, 2004, pp. 393-397. doi:10.1016/j.biombioe.2004.03.002

[5] N. Stalin and H. J. Prabhu, "Performance Test of IC En- gine Using Karanja Biodiesel Blending with Diesel,” ARPN Journal of Engineering and Applied Sciences, Vol. 2, No. 5, 2007, pp. 32-34.

[6] B. Baiju, M. K. Naik and L. M. Das, “A Comparative Evaluation of Compression Ignition Engine Characteristics Using Methyl and Ethyl Esters of Karanja Oil," Renewable Energy, Vol. 34, No. 6, 2009, pp. 1616-1621. doi:10.1016/j.renene.2008.11.020

[7] J. Heywood, "Internal Combustion Engine Fundamentals,” McGraw-Hill, Sigapore, 1988. 